- Original Article

\title{
Joint Effect of Cigarette Smoking and Body Mass Index on White Blood Cell Count in Korean Adults
}

\author{
A-Ra Cho, Won-Jun Choi, Shin-Hye Kim, Jae-Yong Shim, Yong-Jae Lee* \\ Department of Family Medicine, Gangnam Severance Hospital, Yonsei University College of Medicine, Seoul, Korea
}

Background: White blood cell count is an independent risk factor for cardiovascular disease. Several lifestyle and metabolic factors such as cigarette smoking and obesity are known to be associated with an elevated white blood cell count. However, the joint effect of cigarette smoking and obesity on white blood cell count has not yet been fully described.

Methods: We explored the joint effect of cigarette smoking and obesity on white blood cell count using multiple logistic regression analyses after adjusting for confounding variables in a population-based, cross-sectional study of 416,065 Korean adults.

Results: Cigarette smoking and body mass index have a dose-response relationship with a higher white blood cell count, but no synergistic interaction is observed between them (men, P for interaction=0.797; women, P for interaction $=0.311$ ). Cigarette smoking and body mass index might have an additive combination effect on high white blood cell count. Obese male smokers were 2.36 times more likely and obese female smokers 2.35 times more likely to have a high white blood cell count when compared with normal body mass index non-smokers.

Conclusion: Cigarette smoking and body mass index are independently associated with an elevated white blood cell count in both men and women.

Keywords: Leukocyte Count; Smoking; Obesity 


\section{INTRODUCTION}

Several lifestyle factors, including cigarette smoking, alcohol intake, and lack of regular exercise, along with metabolic factors such as obesity, type 2 diabetes, hypertension, and dyslipidemia, are known to be associated with the risk of atherosclerotic cardiovascular disease (CVD). Although the pathogenesis of atherosclerosis and its relation to CVD remains unclear, increasing evidence suggests that arterial inflammation may play a key role in the process of atherosclerosis. ${ }^{1,2)} \mathrm{A}$ high white blood cell (WBC) count has been shown to be an independent predictor of cardiovascular events. Thus, early detection of an elevated WBC count may be important in predicting subsequent CVD morbidity and mortality.

The WBC count, widely evaluated in standard clinical practice, is a nonspecific marker of inflammation and may play an important role in the pathogenesis of arterial injury and the atherosclerotic process. ${ }^{1)}$ Numerous studies in recent decades have revealed that lifestyle and metabolic risk factors are related to an elevated WBC count. For example, it has been demonstrated that current smokers have higher WBC counts than people who have never smoked. ${ }^{3,4)}$ In addition, alcohol intake, ${ }^{5)}$ physical inactivity, ${ }^{6)}$ body mass index (BMI), ${ }^{7)}$ hypertension, ${ }^{8)}$ type 2 diabetes, ${ }^{9)}$ and dyslipidemia ${ }^{10)}$ have been shown to be associated with an elevated WBC count.

The independent effects of lifestyle and metabolic factors on WBC count have been reported in numerous epidemiological studies. ${ }^{3-10)}$ It may be more important whether there is an additive or synergistic effect of lifestyle and metabolic factors on inflammation causing cardiometabolic diseases. However, there has been limited exploration of the combined or interactive effect of lifestyle factors and metabolic factors on WBC count. Therefore, we investigated the possible interactive effects of cigarette smoking and BMI on WBC count in a large, population-based, cross-sectional cohort of 416,065 Koreans (105,505 men and 309,560 women), who underwent medical examination at the request of the National Health Insurance Corporation between 1993 and 1995.

\section{METHODS}

\section{Study Population}

The Korean Cancer Prevention Study (KCPS) is a prospective cohort study designed to assess cancer risk factors by examining disease incidence, mortality, and hospital admissions. The KCPS cohort is primarily composed of government employees, teachers, and their dependents insured by the Korean Medical Insurance Corporation from 1992 through 1995. Subjects had at least one medical examination and completed a questionnaire during that period. The KCPS cohort includes 1,329,525 Koreans (846,907 men and 482,618 women) from 30 to 95 years of age who met the above selection criteria. This study did not include insured workers in its retrospective analysis because the WBC count of these individuals was not recorded during their medical examination. Therefore, the current analysis was limited to insured workers' family dependents in 1993 and 1995 ( $\mathrm{n}=448,978)$. Then, 11,332 subjects whose WBC counts were less than 3,000 cells $/ \mathrm{mm}^{3}$ or more than 11,000 cells $/ \mathrm{mm}^{3}$ were also excluded from this analysis. To avoid confounding the association among smoking, BMI, and WBC count, 13,448 subjects who reported a history of cancer, CVD, respiratory disease, renal disease, and liver disease were also excluded. Additionally, 9,146 subjects with missing data on any covariate information or who had an extremely low BMI $\left(<16.0 \mathrm{~kg} / \mathrm{m}^{2}\right)$ or short stature $(<130$ $\mathrm{cm}$ ) were excluded from the study. After these exclusions, 416,065 participants (105,505 men and 309,560 women) between the ages of 30 and 95 years were included in the final analyses.

\section{Data Collection}

Medical examinations were performed according to a standardized procedure and were conducted by medical staff at local hospitals. In the 1993 and 1995 questionnaires, participants were asked about their smoking habits and other health-related behaviors. Body weight and height were measured with participants wearing light clothing without shoes to the nearest $0.1 \mathrm{~kg}$ and $0.1 \mathrm{~cm}$, respectively. Participants were also asked if they were currently being treated for cancer or other diseases. If so, they were asked for the date of diagnosis. The completed questionnaires were reviewed by trained staff and then entered into a database. WBC count and serum levels of glucose and total cholesterol were measured under fasting conditions for routine clinical purposes. Each hospital had internal and external quality control procedures directed by the Korean Association of Laboratory Quality Control. Smoking exposure was categorized according to smoking status (non-smokers, ex-smokers, and current smokers) and the number of cigarettes per day among current smokers ( 1 to 9,10 to 19 , and 20 or more). BMI $\left(\mathrm{kg} / \mathrm{m}^{2}\right)$ was calculated as the ratio of weight $(\mathrm{kg})$ and height $\left(\mathrm{m}^{2}\right)$, and was divided into seven categories: <18.5, 18.5-19.9, 20.0-21.4, 21.5$22.9,23.0-24.9,25.0-26.9$, and $\geq 27.0 \mathrm{~kg} / \mathrm{m}^{2}$. The total daily alcohol consumption was expressed as the number of glasses per week in relation to Korea's most popular alcoholic beverage, 'soju. One glass of soju contains about $12 \mathrm{~g}$ of ethanol. Alcohol consumption per day was categorized as follows: none (0 g), light (1-14.9 g), and moderate to heavy (15 g or more). Participants were also asked to report if they exercised regularly. WBC counts were quantified using automated blood cell counters (Beckman Coulter, Fullerton, CA, USA) in hospital laboratories. Fasting serum glucose and total cholesterol levels were analyzed using enzymatic methods with an automatic chemistry analyzer (Hitachi 7600-110; Hitachi, Tokyo, Japan). Impaired fasting glucose was defined as $\geq 100$ fasting plasma glucose level $<126 \mathrm{mg} / \mathrm{dL}$. Diabetes was defined from self-reported history or when the fasting serum glucose level was $\geq 126 \mathrm{mg} / \mathrm{dL}$. Pre-hypertension was defined as a systolic pressure of 120-139 mm Hg or a diastolic pressure of 80-89 mm Hg. Hypertension was defined from self-reported history or when systolic blood pressure was $\geq 140 \mathrm{~mm} \mathrm{Hg}$ or diastolic blood pressure was $\geq 90 \mathrm{~mm}$ Hg. Hypercholesterolemia was defined when the fasting serum cholesterol level was $\geq 200 \mathrm{mg} / \mathrm{dL}$. Because the study involved routinely collected medical data, it was not necessary to obtain indi- 
vidual participant consent.

\section{Statistical Analysis}

All statistical analyses were conducted in a gender-specific manner. Age- and BMI-adjusted means of the WBC count for each category of smoking exposure were calculated. The cutoff point for a high WBC count was determined as 7,500 cells $/ \mathrm{mm}^{3}$, which corresponded to the 75th percentile. ${ }^{11)}$ Multiple logistic regression analysis was used to compute odds ratios (ORs) and 95\% confidence intervals (CIs) for high WBC counts, and the $95 \%$ CIs were examined according to the five categories of smoking exposure, seven categories of BMI, three categories of fasting serum glucose levels (normal, impaired fasting glucose, and type 2 diabetes), three categories of blood pressure (normal, pre-hypertension, and hypertension), and four categories of serum cholesterol levels (<160, 160-199, 200-239, and $\geq 240 \mathrm{mg} / \mathrm{dL}$ ). Similarly, ageadjusted proportions of high WBC count per 1,000 persons were calculated and directly standardized to the age distribution of the Korean population in 1995. Further, we explored a possible interactive effect among smoking status, BMI, and gender-influenced metabolic risks on WBC count by using multiple logistic regression analysis. The potential interaction between cigarette smoking and BMI was tested by the multiplicative method. All analyses were conducted using SAS statistical software ver. 8.2 (SAS Institute Inc., Cary, NC, USA). All statistical tests were two-sided and statistical significance was determined at P-value $<0.05$.

Table 1. Clinical characteristics of the study population

\begin{tabular}{lcc}
\hline \multicolumn{1}{c}{ Characteristic } & $\begin{array}{c}\text { Men } \\
(\mathrm{n}=105,505)\end{array}$ & $\begin{array}{c}\text { Women } \\
(\mathrm{n}=309,560)\end{array}$ \\
\hline Age $(\mathrm{y})$ & $61.3 \pm 7.6$ & $53.9 \pm 9.2$ \\
Body mass index $\left(\mathrm{kg} / \mathrm{m}^{2}\right)$ & $22.7 \pm 2.8$ & $24.0 \pm 3.1$ \\
Systolic blood pressure $(\mathrm{mm} \mathrm{Hg})$ & $129.2 \pm 20.8$ & $125.2 \pm 20.6$ \\
Fasting serum glucose $(\mathrm{mg} / \mathrm{dL})$ & $96.9 \pm 33.2$ & $92.9 \pm 27.0$ \\
White blood cell count $\left(\mathrm{celll} / \mathrm{mm}^{3}\right)$ & $7,103 \pm 1,623$ & $6,491 \pm 1,515$ \\
Total cholesterol (mg/dL) & $190.7 \pm 38.8$ & $199.5 \pm 39.6$ \\
Alcohol consumption $(\mathrm{g} / \mathrm{d})$ & & \\
0 & 37.4 & 86.4 \\
0.1-14.9 & 61.8 & 13.5 \\
$\geq 15.0$ & 0.8 & 0.0 \\
Smoking status & & \\
$\quad$ Non-smokers & 20.3 & 92.2 \\
Ex-smokers & 25.4 & 2.5 \\
Current smokers (cigarettes/d) & & \\
$\quad$ 1-9 & 15.7 & 2.9 \\
$\quad$ 10-19 & 22.4 & 1.7 \\
$\quad$ 20 & 16.1 & 0.7 \\
Regular exercise & 31.2 & 18.6 \\
Hypertension* & & 37.7 \\
Type 2 diabetes ${ }^{\dagger}$ & 46.3 & 5.5 \\
\hline
\end{tabular}

Values are presented as mean \pm standard deviation or $\%$, unless otherwise indicated. *Defined as systolic blood pressure $140 \mathrm{~mm} \mathrm{Hg}$ and/or diastolic blood pressure $\geq 90$ $\mathrm{mm} \mathrm{Hg}$ or a history of the disorder. ${ }^{\dagger}$ Defined as fasting serum glucose level $\geq 126$ $\mathrm{mg} / \mathrm{dL}$ or a history of the disorder.

\section{RESULTS}

Table 1 shows the general characteristics of the study population, which consisted of about three times as many women as men. The mean BMI $\left(\mathrm{kg} / \mathrm{m}^{2}\right)$ of the study population was 22.7 for men and 24.0 for women. About $19.9 \%$ of men and $32.0 \%$ of women had a BMI $\geq 25.0$ $\mathrm{kg} / \mathrm{m}^{2}$, and $7.2 \%$ of men and $16.2 \%$ of women had a BMI $\geq 27.0 \mathrm{~kg} / \mathrm{m}^{2}$. Both cigarette smoking and alcohol use were substantially more common in men than in women. Systolic blood pressure and levels of fasting serum glucose and total cholesterol were also higher in men than in women.

Figure 1 shows the age-adjusted means of WBC count (cells $/ \mathrm{mm}^{3}$ ) according to BMI categories and smoking history. The mean WBC count was higher in ever-smokers among both men and women. Moreover, the mean WBC counts gradually increased with increasing BMI levels irrespective of smoking status in both men and women (all P for trends $<0.001$ ).

Table 2 shows the effects of lifestyle risks (smoking exposure, alcohol intake, and lack of regular exercise) and metabolic risks (high BMI, fasting serum glucose levels, blood pressure, and total cholesterol levels) on high WBC count. The findings show that smoking exposure had a strong, positive, dose-response tendency in men and women. Men and women who smoked 20 or more cigarettes per day were 2.34 times and 2.20 times more likely to have a high WBC count compared with non-smokers, respectively. Regular exercise had an inverse association with a high WBC count in both men and women, whereas light alcohol consumption ( $<15 \mathrm{~g} / \mathrm{d}$ ) had an inconsistent association with WBC count among both men and women. All four metabolic risks included in our analyses were also significantly associated with a high WBC count. The relative risks for high WBC count increased progressively with increasing BMI levels in both men and women. The association between high serum glucose levels and high WBC count was also significant in men and women. In addition, individuals with hy-

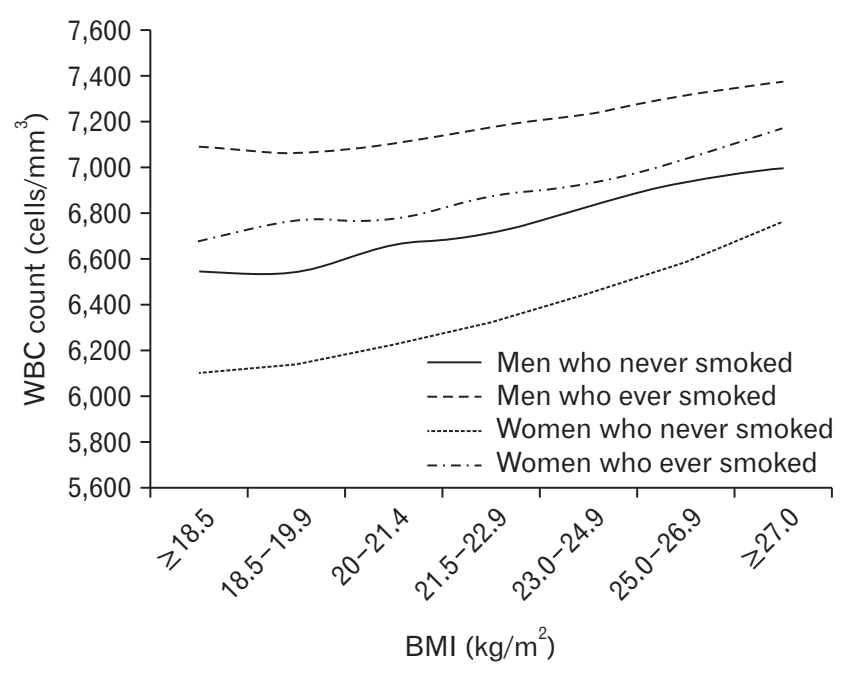

Figure 1. Age-adjusted means of WBC count (cells/mm³) according to BMI category and smoking history. WBC, white blood cell; BMl, body mass index. 
Table 2. Age-adjusted proportion* per 1,000 persons and $\mathrm{OR}^{\dagger}$ for high $\mathrm{WBC}$ count ${ }^{\ddagger}$ as a dependent variable and the associated factors as independent variables among men and women

\begin{tabular}{|c|c|c|c|c|}
\hline \multirow[b]{2}{*}{ Characteristic } & \multicolumn{2}{|c|}{ Men $(n=105,505)$} & \multicolumn{2}{|c|}{ Women $(n=309,560)$} \\
\hline & $\begin{array}{l}\text { Age-adjusted proportion } \\
\text { per } 1,000 \text { persons }\end{array}$ & Adjusted OR (95\% Cl) & $\begin{array}{l}\text { Age-adjusted proportion } \\
\text { per 1,000 persons }\end{array}$ & Adjusted OR $(95 \% \mathrm{Cl})$ \\
\hline \multicolumn{5}{|l|}{ Lifestyle factors } \\
\hline \multicolumn{5}{|l|}{ Smoking exposure } \\
\hline Non-smokers & 281.5 & 1.00 & 229.0 & 1.00 \\
\hline Ex-smokers (cigarettes/d) & 302.6 & $1.11(1.06-1.16)$ & 263.4 & $1.26(1.20-1.33)$ \\
\hline $1-9$ & 389.2 & $1.59(1.51-1.67)$ & 318.9 & $1.67(1.60-1.75)$ \\
\hline $10-19$ & 428.6 & $1.92(1.84-2.01)$ & 349.4 & $1.83(1.73-1.94)$ \\
\hline$\geq 20$ & 494.4 & $2.34(2.23-2.46)$ & 376.4 & $2.20(2.01-2.41)$ \\
\hline \multicolumn{5}{|l|}{ Alcohol intake (g/d) } \\
\hline Non-drinkers & 365.8 & 1.00 & 231.6 & 1.00 \\
\hline $1-14.9$ & 383.7 & $0.96(0.93-0.99)$ & 256.7 & $1.09(1.06-1.12)$ \\
\hline$\geq 15.0$ & 430.6 & $0.95(0.80-1.12)$ & NE & NE \\
\hline \multicolumn{5}{|l|}{ Regular exercise } \\
\hline No & 389.8 & 1.00 & 250.3 & 1.00 \\
\hline Yes & 350.4 & $0.91(0.88-0.94)$ & 193.8 & $0.91(0.89-0.93)$ \\
\hline \multicolumn{5}{|l|}{ Metabolic factors } \\
\hline \multicolumn{5}{|l|}{$\mathrm{BMl}\left(\mathrm{kg} / \mathrm{m}^{2}\right)$} \\
\hline$<18.5$ & 358.0 & $1.04(0.96-1.12)$ & 183.5 & $0.96(0.90-1.02)$ \\
\hline $18.5-19.9$ & 338.1 & 1.00 & 187.6 & 1.00 \\
\hline $20.0-21.4$ & 352.8 & $1.07(1.02-1.14)$ & 193.5 & $1.02(0.98-1.06)$ \\
\hline $21.5-22.9$ & 363.1 & $1.15(1.09-1.21)$ & 211.3 & $1.11(1.07-1.16)$ \\
\hline $23.0-24.9$ & 382.0 & $1.21(1.16-1.28)$ & 231.6 & $1.23(1.18-1.28)$ \\
\hline $25.0-26.9$ & 403.4 & $1.31(1.24-1.39)$ & 256.0 & $1.39(1.34-1.45)$ \\
\hline$\geq 27.0$ & 427.5 & $1.32(1.23-1.41)$ & 299.6 & $1.64(1.58-1.71)$ \\
\hline \multicolumn{5}{|l|}{$\mathrm{FSG}(\mathrm{mg} / \mathrm{dL})$} \\
\hline Normal & 373.3 & 1.00 & 226.3 & 1.00 \\
\hline Impaired fasting glucose $\mathrm{s}^{\S}$ & 392.9 & $1.07(1.01-1.12)$ & 276.8 & $1.19(1.15-1.23)$ \\
\hline Type 2 diabetes" & 420.8 & $1.16(1.11-1.22)$ & 340.3 & $1.62(1.56-1.67)$ \\
\hline \multicolumn{5}{|l|}{ Blood pressure $(\mathrm{mm} \mathrm{Hg})$} \\
\hline Normal & 357.7 & 1.00 & 208.2 & 1.00 \\
\hline Pre-hypertension? & 374.7 & $1.06(1.02-1.11)$ & 230.4 & $1.09(1.06-1.11)$ \\
\hline Hypertension ${ }^{\star \star}$ & 395.6 & $1.11(1.07-1.15)$ & 261.3 & $1.20(1.17-1.23)$ \\
\hline \multicolumn{5}{|l|}{ Total cholesterol (mg/dL) } \\
\hline$<160$ & 331.5 & 1.00 & 193.3 & 1.00 \\
\hline 160-199 & 367.2 & $1.16(1.12-1.22)$ & 222.1 & $1.15(1.12-1.18)$ \\
\hline $200-239$ & 401.9 & $1.32(1.27-1.38)$ & 248.2 & $1.25(1.22-1.29)$ \\
\hline$\geq 240$ & 436.5 & $1.46(1.43-1.50)$ & 286.1 & $1.44(1.40-1.49)$ \\
\hline
\end{tabular}

OR, odds ratio; WBC, white blood cell; Cl, confidence interval; NE, not estimated due to the small number of subjects; BMI, body mass index; FSG, fasting serum glucose; SBP, systolic blood pressure; DBP, diastolic blood pressure.

${ }^{*}$ The proportion per 1,000 persons is given, standardized according to the age distribution of Korea's national population in 1995. ${ }^{\dagger} \mathrm{OR}$ and $95 \%$ Cls from multiple logistic regression analysis after adjusting for age, smoking exposure, alcohol intake, BMl, fasting plasma glucose levels, blood pressure, and total cholesterol levels. ${ }^{\ddagger}$ The cutoff for high WBC count was determined as 7,500 cells $/ \mathrm{mm}^{3}$, which corresponded to the 75 th percentile. ${ }^{\S}$ Defined as $\geq 100$ fasting plasma glucose level $<126 \mathrm{mg} / \mathrm{dL}$. "Defined as FSG level of at least $126 \mathrm{mg} / \mathrm{dL}$ or a history of the disorder. "Defined as $\geq 120 \mathrm{SBP}<140 \mathrm{~mm} \mathrm{Hg}$ and/or $\geq 80 \mathrm{DBP}<90 \mathrm{~mm} \mathrm{Hg}$. ${ }^{* *}$ Defined as SBP $\geq 140 \mathrm{~mm} \mathrm{Hg}, \mathrm{DBP} \geq 90 \mathrm{~mm}$ $\mathrm{Hg}$, or a history of the disorder.

pertension and pre-hypertension had significant associations with a high WBC count among both men and women. Moreover, the association between a high serum cholesterol level and high WBC count was also significant in both men and women.

We explored patterns of the joint effect of cigarette smoking and BMI on WBC count. Table 3 shows the OR estimates for the strata as defined by nine pairs of three categories of smoking status and three categories of BMI. The highest OR for a high WBC count was observed among current smokers who had a BMI $\geq 25.0 \mathrm{~kg} / \mathrm{m}^{2}$. Obese male smokers were 2.36 times more likely and obese female smokers were 2.35 times more likely to have a high WBC count when compared with non-smokers with a normal BMI. Therefore, cigarette smoking and BMI seem to have an additive combined effect on high WBC count but no synergistic interaction (men, $\mathrm{P}$ for interaction=0.797; women, $\mathrm{P}$ for interaction=0.311). 
Table 3. Combined effect of cigarette smoking and BMl on high WBC count*

\begin{tabular}{|c|c|c|c|c|c|}
\hline \multirow{2}{*}{ Variable 1} & \multirow{2}{*}{ Variable 2} & \multicolumn{2}{|c|}{ Men $(n=105,505)$} & \multicolumn{2}{|c|}{ Women $(n=309,560)$} \\
\hline & & Adjusted OR $(95 \% \mathrm{Cl})^{\dagger}$ & $\mathrm{P}$ for interaction & Adjusted OR $(95 \% \mathrm{Cl})^{\dagger}$ & $\mathrm{P}$ for interaction \\
\hline Smoking status & $\mathrm{BMl}\left(\mathrm{kg} / \mathrm{m}^{2}\right)$ & & 0.797 & & 0.311 \\
\hline Non-smoker & $<23.0$ & 1.00 & & 1.00 & \\
\hline Non-smoker & $23.0-24.9$ & $1.09(1.01-1.18)$ & & $1.16(1.13-1.19)$ & \\
\hline Non-smoker & $\geq 25.0$ & $1.19(1.10-1.28)$ & & $1.43(1.40-1.47)$ & \\
\hline Ex-smoker & $<23.0$ & $1.12(1.05-1.19)$ & & $1.33(1.22-1.45)$ & \\
\hline Ex-smoker & $23.0-24.9$ & $1.28(1.14-1.31)$ & & $1.45(1.30-1.62)$ & \\
\hline Ex-smoker & $\geq 25.0$ & $1.37(1.24-1.43)$ & & $1.70(1.56-1.85)$ & \\
\hline Current smoker & $<23.0$ & $1.82(1.73-1.92)$ & & $1.86(1.77-1.95)$ & \\
\hline Current smoker & $23.0-24.9$ & $2.07(1.96-2.21)$ & & $2.11(1.96-2.28)$ & \\
\hline Current smoker & $\geq 25.0$ & $2.36(2.21-2.51)$ & & $2.35(2.19-2.51)$ & \\
\hline
\end{tabular}

BMl, body mass index; WBC, white blood cell; OR, odds ratio; $\mathrm{Cl}$, confidence interval.

${ }^{*}$ The cutoff points of high WBC count were determined as $7,500 \mathrm{cells} / \mathrm{mm}^{3}$, which corresponded to the 75 th percentile. ${ }^{\dagger} 0 \mathrm{R}$ and $95 \% \mathrm{Cl}$ from multiple logistic regression analysis after adjusting for age, alcohol intake, regular exercise, fasting serum glucose, blood pressure, and total cholesterol.

\section{DISCUSSION}

In this large, population-based cross-sectional study, cigarette smoking and BMI were found to be independently associated with WBC count with an additive combined effect. Among lifestyle factors, cigarette smoking had a prominent dose-response relationship with a high WBC count for both men and women. Our results also showed that the WBC count was high even in ex-smokers. This observed association is in agreement with most recent studies on this topic. Kawada ${ }^{12)}$ reported that the WBC count was higher in smokers and ex-smokers than in non-smokers, and elevated WBC counts were maintained for several years after cessation of smoking. The mechanism underlying the smoking-induced increase in WBC count remains unclear. Chronic smoking stimulates the airway tract and may increase the WBC count. ${ }^{13)}$ Light alcohol consumption $(<15 \mathrm{~g} / \mathrm{d})$ decreased the OR for high WBC count in men, but not in women. Light alcohol consumption and casual drinking, but not binge or heavy alcohol consumption, has been reported to have significant beneficial effects on inflammatory markers. ${ }^{5)}$ However, because our study did not distinguish between normal causal and binge drinking patterns, the association between alcohol consumption and WBC counts should be interpreted cautiously. The OR for high WBC counts was also significantly decreased in both men and women who exercised regularly. Regular exercise has a beneficial and favorable impact on abdominal fat accumulation, blood pressure, insulin sensitivity, dyslipidemia, and inflammatory markers. ${ }^{6,14-17)}$ Since WBC count is strongly influenced by body fat, it may be equally plausible that lower WBC counts are an intermediate consequence of the effect of exercise on reduced body fat tissue.

Among metabolic factors, all four metabolic risks were found to be associated with high WBC counts among both men and women. The increase in WBC count according to BMI categories could also be explained by pro-inflammatory cytokines including interleukin- 6 and tumor necrosis factor- $\alpha$, which are expressed in adipose tissue and stimulate the WBC count. ${ }^{18)}$ Hypertension and pre-hypertension were found to be significantly associated with the WBC count in both men and women. Recent studies have shown that the WBC count is associated with hypertension and high normal blood pressure. ${ }^{19,20)}$ Although, the role of WBCs in hypertension remains unclear, inflammation may contribute to increasing microvascular capillary resistance, reducing endothelial reactivity, and increasing catecholamine levels, which can increase blood pressure. ${ }^{21-23)}$

Obesity is a state in which there is an increased storage of fatty acids in the form of triglycerides in adipose tissue. ${ }^{24)}$ Continuous release of fatty acid from stored triglycerides causes dyslipidemia and drives gluconeogenesis in the liver. ${ }^{25-27)}$ Abdominal obesity, therefore, may be considered an important causal link between cardiovascular risk factors and high WBC count. In this regard, we explored the possible interactive effect of cigarette smoking as a representative of lifestyle factors and BMI as a representative of metabolic factors; however, we found that cigarette smoking and BMI were independently associated with WBC count, and no interaction was found between them in the current study. Therefore, cigarette smoking and BMI might have had an additive combined effect on high WBC count but no synergistic interaction

Our study has several limitations. First, only one measurement of WBC count, from a baseline examination, was included in the analysis. Therefore, it was not possible to determine whether an acute, brief episode of inflammation or chronic inflammation was responsible for the correlation found in the current study. In addition, the effects of drugs such as aspirin or non-steroidal anti-inflammatory drugs, which can influence WBC count, were not fully adjusted for in the multiple logistic regression model. To minimize these errors, we excluded subjects with a WBC count exceeding 11,000 cells $/ \mathrm{mm}^{3}$. However, it is important to note that although the WBC count varies daily, a single measurement has been shown to predict risk for death and specific diseases, including cancer and CVD. ${ }^{28,29)}$ Further, random misclassification because of biological variability may result in the underestimation of true associations, but this limitation does not explain our results. Second, information on the measurement of abdominal adiposity, such as waist circumference, was not available; consequently, we 
could not determine whether the increased WBC count associated with increased BMI depended on overall adiposity, specific adipose tissue, or a distribution pattern. Lastly, the study population, particularly the older population, might not be representative of the general population in Korea. However, since the sample size was quite large, we were able to investigate the relationship between a wide range of lifestyle and metabolic factors and WBC count. Because of these advantages, we found that each metabolic factor, even in the high normal range, was associated with $\mathrm{WBC}$ count.

In conclusion, our study demonstrated that cigarette smoking and BMI were independently associated with high WBC count, showing an additive combined effect.

\section{CONFLICT OF INTEREST}

No potential conflict of interest relevant to this article was reported.

\section{REFERENCES}

1. Ross R. Atherosclerosis: an inflammatory disease. N Engl J Med 1999;340:115-26.

2. Libby P, Ridker PM, Maseri A. Inflammation and atherosclerosis. Circulation 2002;105:1135-43.

3. Corre F, Lellouch J, Schwartz D. Smoking and leucocyte-counts: results of an epidemiological survey. Lancet 1971;2:632-4.

4. Petitti DB, Kipp H. The leukocyte count: associations with intensity of smoking and persistence of effect after quitting. Am J Epidemiol 1986;123:89-95.

5. Nakanishi N, Yoshida H, Okamoto M, Matsuo Y, Suzuki K, Tatara K. Association of alcohol consumption with white blood cell count: a study of Japanese male office workers. J Intern Med 2003;253:367-74.

6. Verdaet D, Dendale P, De Bacquer D, Delanghe J, Block P, De Backer G. Association between leisure time physical activity and markers of chronic inflammation related to coronary heart disease. Atherosclerosis 2004;176:303-10.

7. Herishanu Y, Rogowski O, Polliack A, Marilus R. Leukocytosis in obese individuals: possible link in patients with unexplained persistent neutrophilia. Eur J Haematol 2006;76:516-20.

8. Mugge A, Lopez JA. Do leukocytes have a role in hypertension? Hypertension 1991;17:331-3.

9. Nakanishi N, Yoshida H, Matsuo Y, Suzuki K, Tatara K. White bloodcell count and the risk of impaired fasting glucose or type II diabetes in middle-aged Japanese men. Diabetologia 2002;45:42-8.

10. Lohsoonthorn V, Dhanamun B, Williams MA. Prevalence of metabolic syndrome and its relationship to white blood cell count in a population of Thai men and women receiving routine health examinations. Am J Hypertens 2006;19:339-45.

11. Ishizaka N, Ishizaka Y, Toda E, Nagai R, Yamakado M. Association between cigarette smoking, white blood cell count, and metabolic syndrome as defined by the Japanese criteria. Intern Med 2007;46:116770 .

12. Kawada T. Smoking-induced leukocytosis can persist after cessation of smoking. Arch Med Res 2004;35:246-50.

13. Martey CA, Pollock SJ, Turner CK, O'Reilly KM, Baglole CJ, Phipps RP, et al. Cigarette smoke induces cyclooxygenase-2 and microsomal prostaglandin E2 synthase in human lung fibroblasts: implications for lung inflammation and cancer. Am J Physiol Lung Cell Mol Physiol 2004;287:L981-91.

14. Pratley RE, Hagberg JM, Dengel DR, Rogus EM, Muller DC, Goldberg AP. Aerobic exercise training-induced reductions in abdominal fat and glucose-stimulated insulin responses in middle-aged and older men. J Am Geriatr Soc 2000;48:1055-61.

15. Liu S, Manson JE. Dietary carbohydrates, physical inactivity, obesity, and the 'metabolic syndrome' as predictors of coronary heart disease. Curr Opin Lipidol 2001;12:395-404.

16. Stewart KJ. Exercise training and the cardiovascular consequences of type 2 diabetes and hypertension: plausible mechanisms for improving cardiovascular health. JAMA 2002;288:1622-31.

17. Imperatore G, Cheng YJ, Williams DE, Fulton J, Gregg EW. Physical activity, cardiovascular fitness, and insulin sensitivity among U.S. adolescents: the National Health and Nutrition Examination Survey, 19992002. Diabetes Care 2006;29:1567-72.

18. Sharma AM. Adipose tissue: a mediator of cardiovascular risk. Int J Obes Relat Metab Disord 2002;26 Suppl 4:S5-7.

19. Friedman GD, Selby JV, Quesenberry CP Jr. The leukocyte count: a predictor of hypertension. J Clin Epidemiol 1990;43:907-11.

20. Shankar A, Klein BE, Klein R. Relationship between white blood cell count and incident hypertension. Am J Hypertens 2004;17:233-9.

21. Orakzai RH, Orakzai SH, Nasir K, Santos RD, Rana JS, Pimentel I, et al. Association of white blood cell count with systolic blood pressure within the normotensive range. J Hum Hypertens 2006;20:341-7.

22. Gillum RF, Mussolino ME. White blood cell count and hypertension incidence: the NHANES I epidemiologic follow-up study. J Clin Epidemiol 1994;47:911-9.

23. Elkind MS, Sciacca RR, Boden-Albala B, Tondella ML, Feikin DR, Fields BS, et al. Leukocyte count is associated with reduced endothelial reactivity. Atherosclerosis 2005;181:329-38.

24. Rosenbaum M, Leibel RL, Hirsch J. Obesity. N Engl J Med 1997;337: 396-407.

25. Syvanne M, Taskinen MR. Lipids and lipoproteins as coronary risk factors in non-insulin-dependent diabetes mellitus. Lancet 1997;350 Suppl 1:SI20-3.

26. Boden G. Effects of free fatty acids on gluconeogenesis and glycogenolysis. Life Sci 2003;72:977-88.

27. Staehr P, Hother-Nielsen O, Landau BR, Chandramouli V, Holst JJ, Beck-Nielsen $\mathrm{H}$. Effects of free fatty acids per se on glucose production, gluconeogenesis, and glycogenolysis. Diabetes 2003;52:260-7.

28. Jee SH, Park JY, Kim HS, Lee TY, Samet JM. White blood cell count and risk for all-cause, cardiovascular, and cancer mortality in a cohort of Koreans. Am J Epidemiol 2005;162:1062-9.

29. Lee CD, Folsom AR, Nieto FJ, Chambless LE, Shahar E, Wolfe DA. White blood cell count and incidence of coronary heart disease and ischemic stroke and mortality from cardiovascular disease in AfricanAmerican and White men and women: atherosclerosis risk in communities study. Am J Epidemiol 2001;154:758-64. 